\title{
Combining innovative experimental approaches and cross-scale reactive transport modelling for assessing coupled hydrogeochemical processes at interfaces in deep geological repositories for radioactive waste
}

Jenna Poonoosamy et al.

Correspondence to: Jenna Poonoosamy (j.poonoosamy@fz-juelich.de)

The copyright of individual parts of the supplement might differ from the article licence. 
COMBINING INNOVATIVE EXPERIMENTAL APPROACHES AND CROSS-SCALE REACTIVE TRANSPORT MODELLING FOR ASSESSING COUPLED HYDROGEOCHEMICAL PROCESSES AT INTERFACES IN DEEP GEOLOGICAL REPOSITORIES FOR RADIOACTIVE WASTES

JENNA POONOOSAMY, MARTINA KLINKENBERG, MARA LÖNARTZ, YUANKAI YANG, GUIDO DEISSMANN, FELIX BRANDT AND DIRK BOSBACH

Institute of Energy and Climate Research (IEK-6), Forschungszentrum Jülich GmbH, 52425 Jülich, Germany 


\section{MOTIVATION}

Understanding of dissolution/precipitation processes in porous media and coupling to transport properties is necessary for the assessment of the performance of engineered and natural barriers in nuclear waste repositories

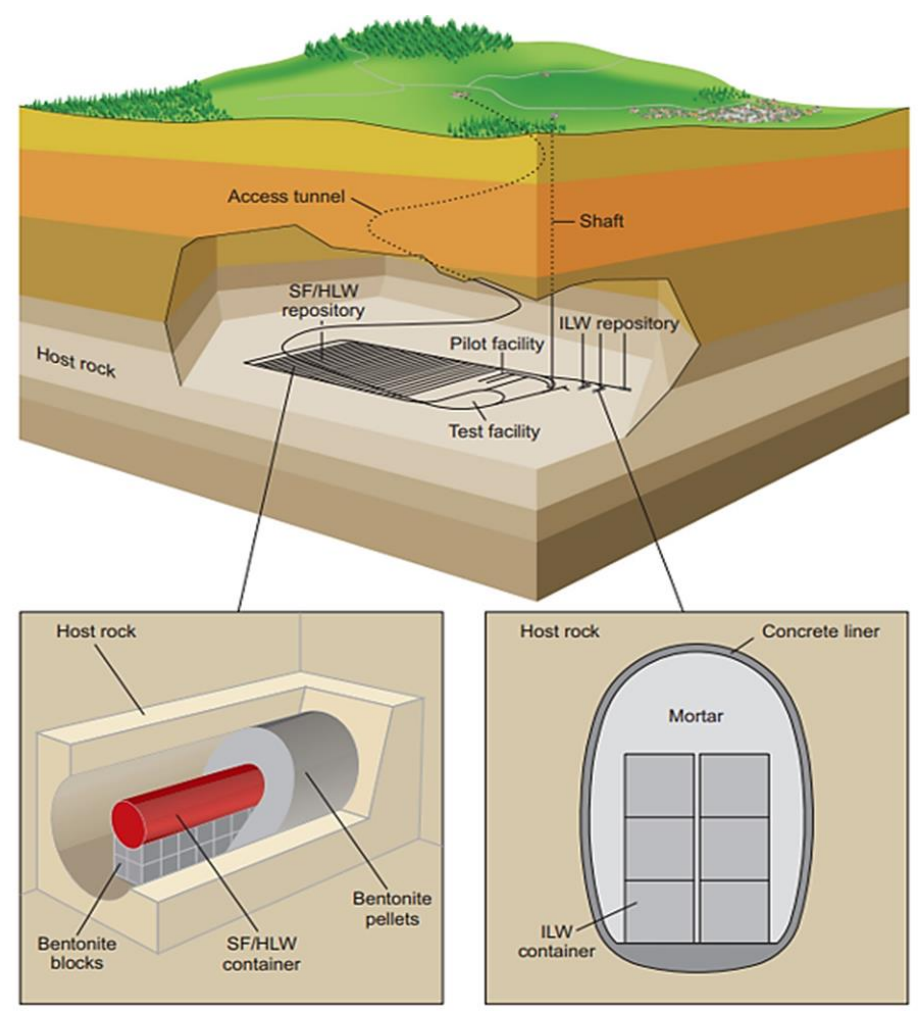

- Reactive Transport Modelling can predict the fate of radionuclides in space \& time

www.nagra.ch 


\section{COUPLING OF POROSITY TO TRANSPORT PROPERTIES}

\section{The classical approach}

dissolution/precipitation of minerals

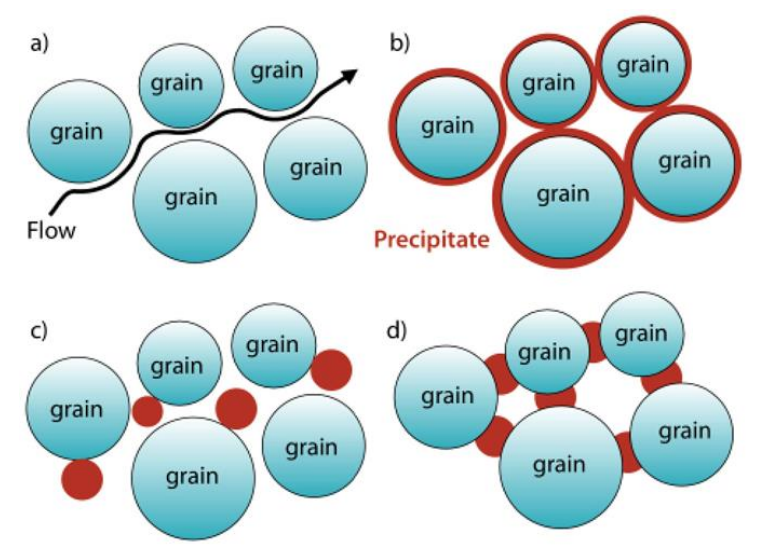

Need of experimental benchmarks:

- to evaluate implementations in reactive transport models

- to build confidence in the predictions of reactive transport models

\section{porosity changes}

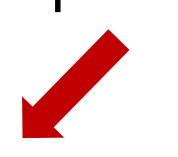

permeability diffusivity

Kozeny-Carman equation Archie's law

\section{classical approaches}




\section{EXPERIMENTAL DESIGN \& CONCEPT}

\section{Mineral precipitation and consequences on permeability}

Investigation of the effect of supersaturation on precipitation processes in porous media

Flow through column

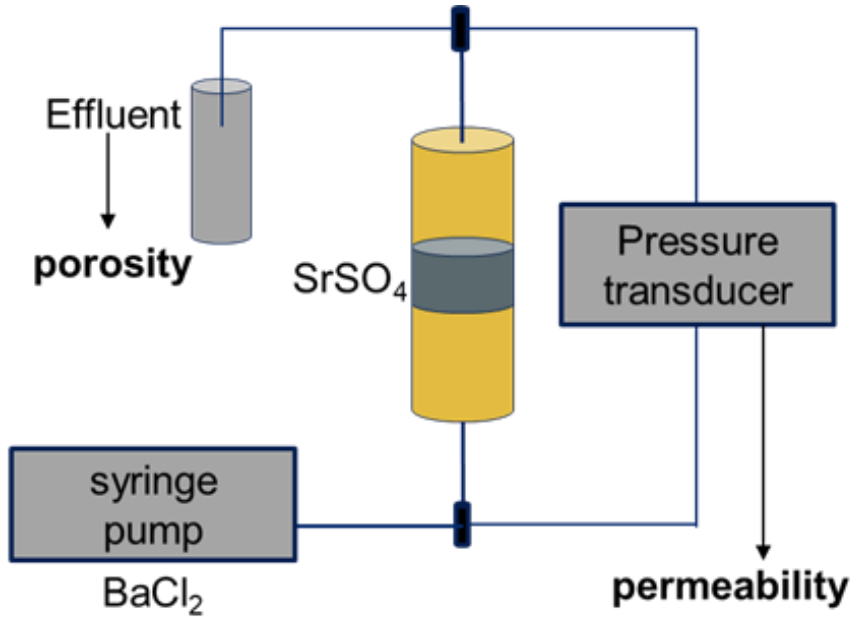

$$
\mathrm{SrSO}_{4(\mathrm{~s})}+\mathrm{Ba}^{2+}{ }_{(\mathrm{aq})} \rightarrow \mathrm{Sr}^{2+}{ }_{(\mathrm{aq})}+\mathrm{BaSO}_{4(\mathrm{~s})}
$$

molar volume $\mathrm{BaSO}_{4}>$ molar volume $\mathrm{SrSO}_{4}$

$\rightarrow$ porosity \& permeability decrease

3 experiments: $100 \mathrm{mM} \mathrm{Ba}(\exp .1)$,

$10 \mathrm{mM} \mathrm{Ba}$ (exp. 2), $1 \mathrm{mM} \mathrm{Ba}$ (exp. 3)
Nuclear Magnetic Resonance Imaging (MRI)

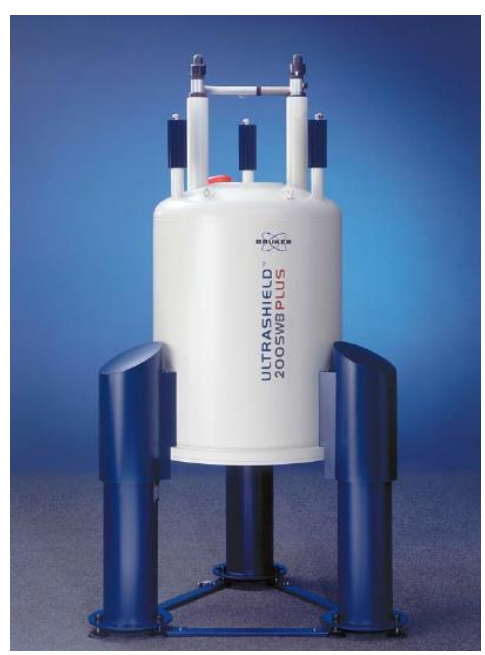

Assessing porosity and pore connectivity changes using high field MRI $\left(\mathrm{B}_{0}=4.7 \mathrm{~T}\right)$ 


\section{POROSITY - PERMEABILITY CHANGES}
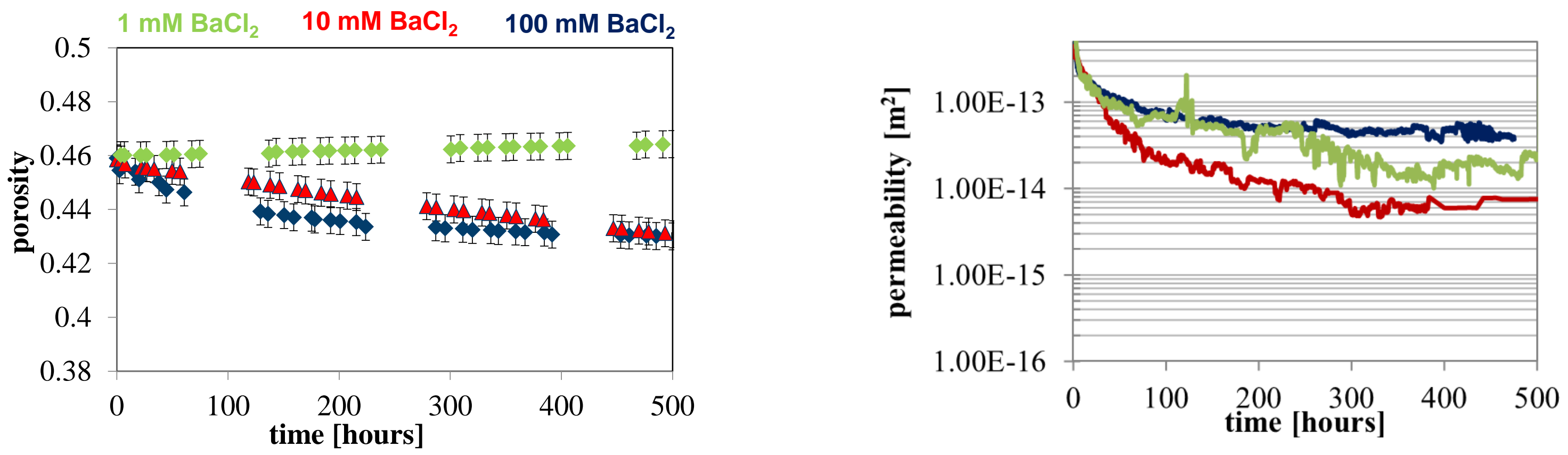

- In experiment 1 and 2 , similar porosity, but permeability differs by 1 order of magnitude

- In experiment 3, porosity remains constant, but permeability decreases by 2 orders of magnitude

$>$ Small changes in porosity cause significant changes in permeability 


\section{MICROSTRUCTURAL CHANGES}

EDX elemental map of the reacted celestine zone with secondary barite overgrowth
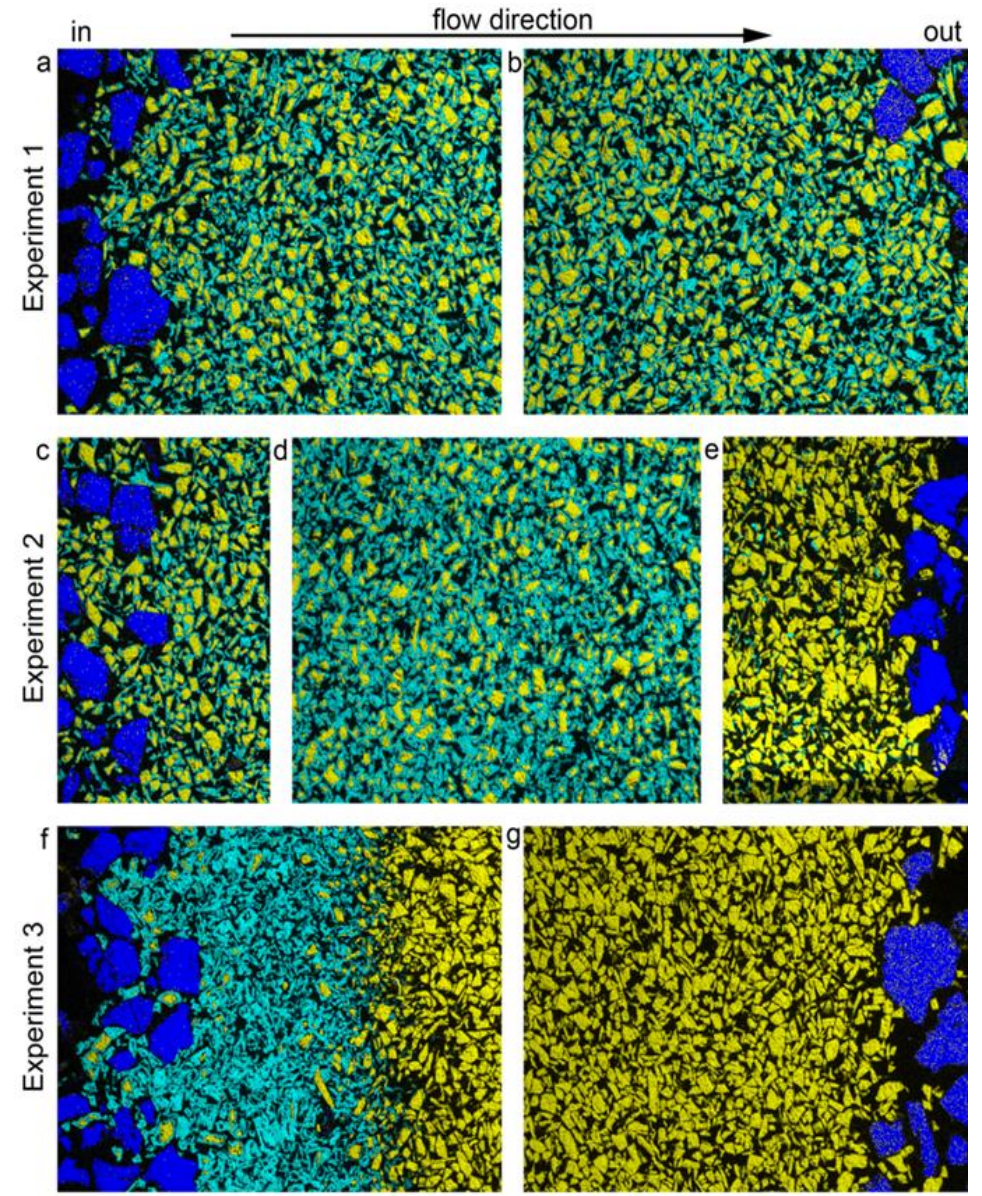

$\mathrm{Ba}$

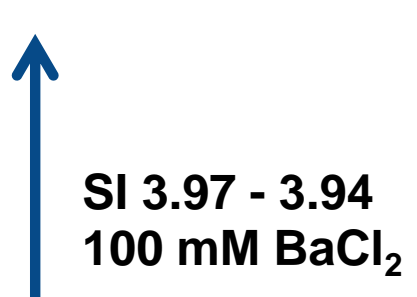

SI $3.82-0.344$

$10 \mathrm{mM} \mathrm{BaCl}_{2}$

SI $3.35-0.277$

$1 \mathrm{mM} \mathrm{BaCl}_{2}$

Saturation Index

$200 \mu \mathrm{m}$
- 100 mM Ba: uniform $\mathrm{BaSO}_{4}$ distribution
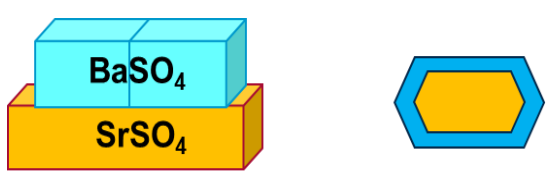

- 10 mM Ba: non-uniform $\mathrm{BaSO}_{4}$ distribution

- $1 \mathrm{mM}$ Ba: new pore architecture

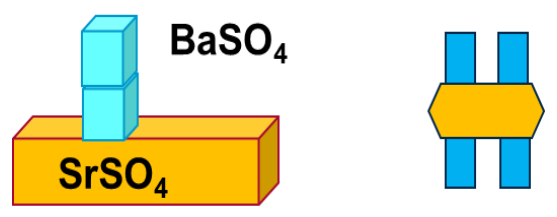

Mineral growth mechanism influences the change in pore architecture and consequently permeability

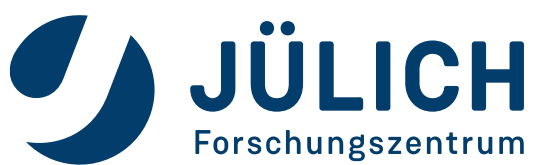




\section{EVALUATION OF POROSITY - PERMEABILITY COUPLING}



- Simulations using modified Kozeny-Carman equation failed to predict permeability changes

$$
k=k_{0}\left(\frac{\emptyset}{\emptyset_{0}}\right)^{3}\left(\frac{1-\emptyset_{0}}{1-\varnothing}\right)^{2}
$$

- Alternative porosity - permeability relation (Verma \& Pruess 1988) :

$$
k=k_{0}\left(\frac{\emptyset-\emptyset_{\text {critical }}}{\emptyset_{0}-\emptyset_{\text {critical }}}\right)^{n}
$$

$k_{0}$ initial permeability; $\emptyset_{0}$ initial porosity

$$
\emptyset_{\text {critical }} \text { critical porosity }
$$

$1 \leq n \leq 6$, for $0.8 \emptyset_{0} \leq \emptyset_{\text {critical }} \leq 0.9 \emptyset_{0}$

$\emptyset_{\text {critical }}$ and $\mathrm{n}$ set to 0.38 and 4 to match experimental data 


\section{EVALUATION OF POROSITY - PERMEABILITY COUPLING}

Reactive transport modelling using Open-GeoSys-GEMs

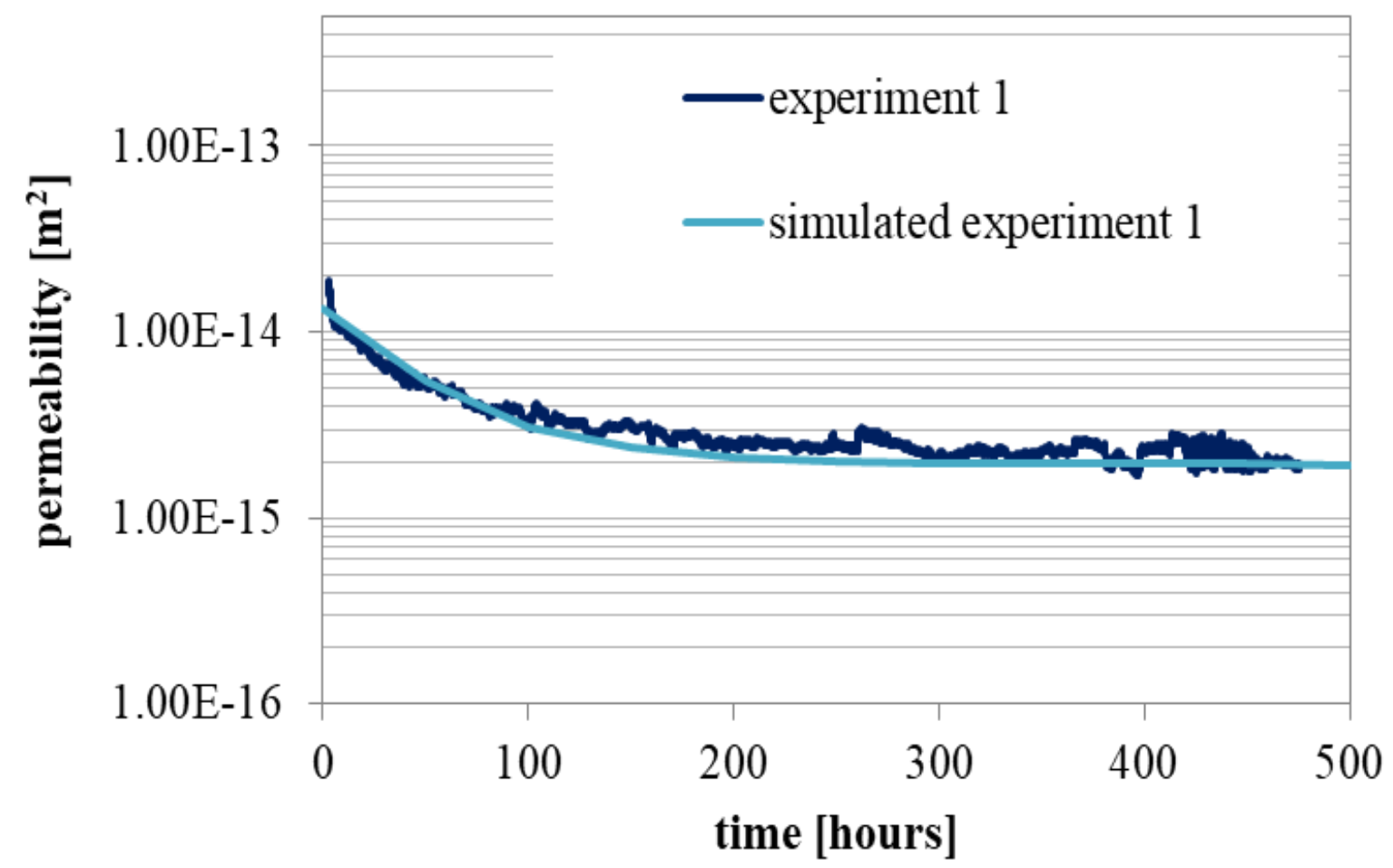

- Simulations using modified Kozeny-Carman equation failed to predict permeability changes

- More sophisticated porosity/permeability relationship involving a critical porosity required to describe permeability changes due to precipitation processes

- What is the physical meaning of critical porosity? 


\section{VISUALISATION OF POROSITY CHANGES BY MRI}

\section{Temporal evolution of porosity}

day after start
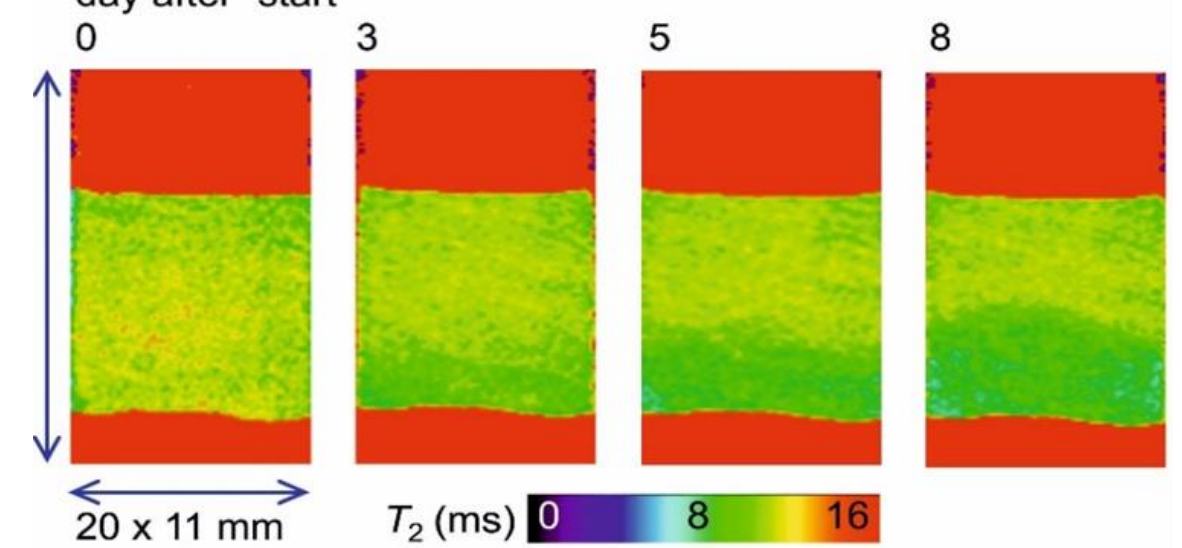

day after start

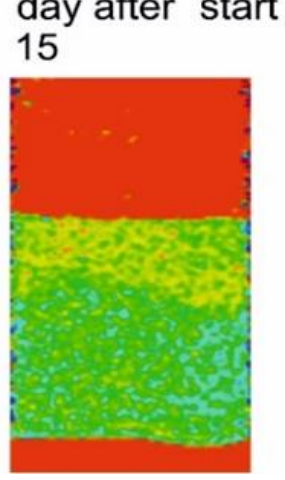

$21 \quad 30$



- 2D relaxometry measurements show a decrease in porosity with time

- Clogging zones, need to be upscaled $\rightarrow$ so-called critical porosity

Can the concept behind the Verma and Pruess relationship be applied for a diffusive system? 


\section{EXPERIMENTAL DESIGN \& CONCEPT}

\section{Mineral precipitation and consequences on diffusivity}

Microfluidic experiment

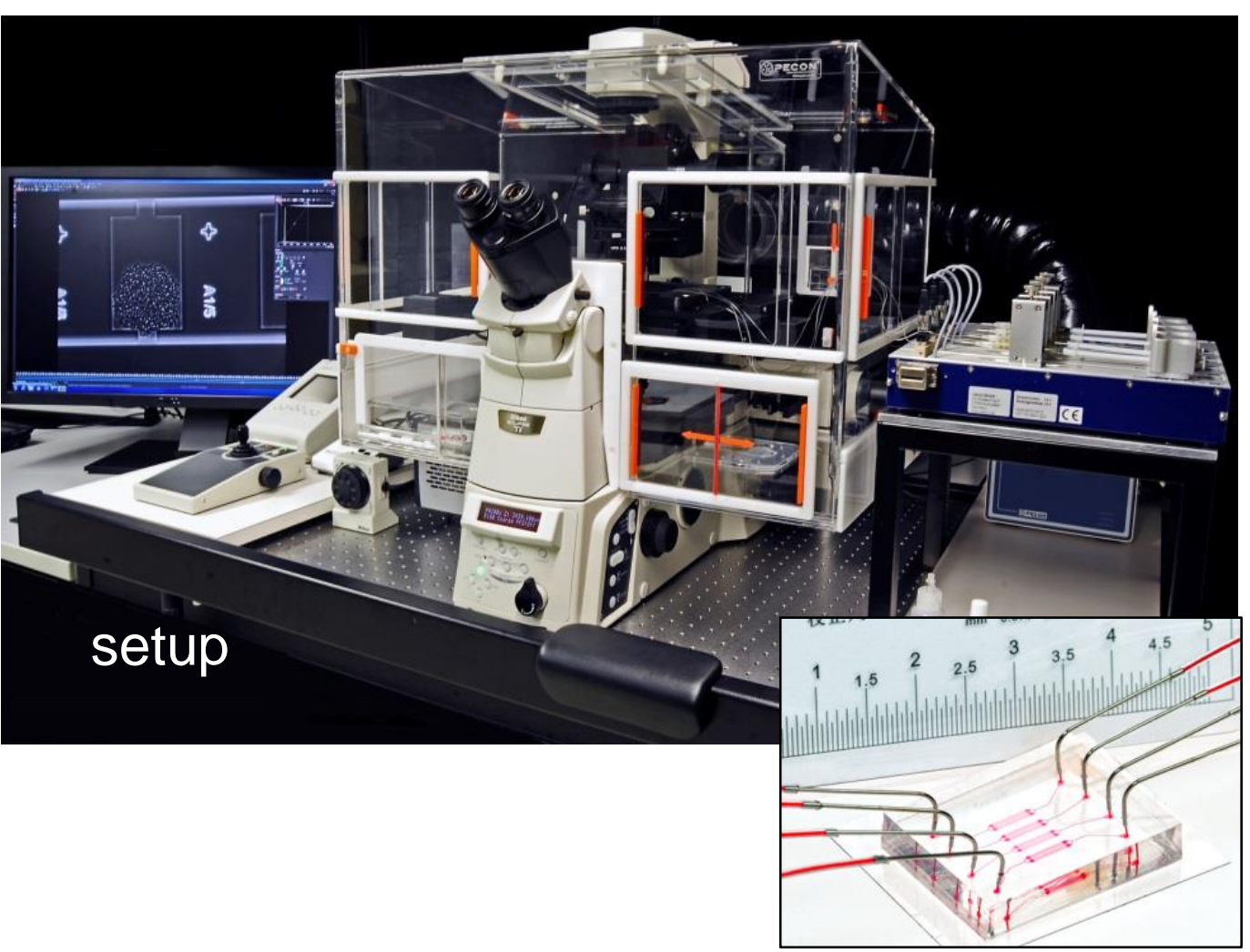

microreactor
Chip design

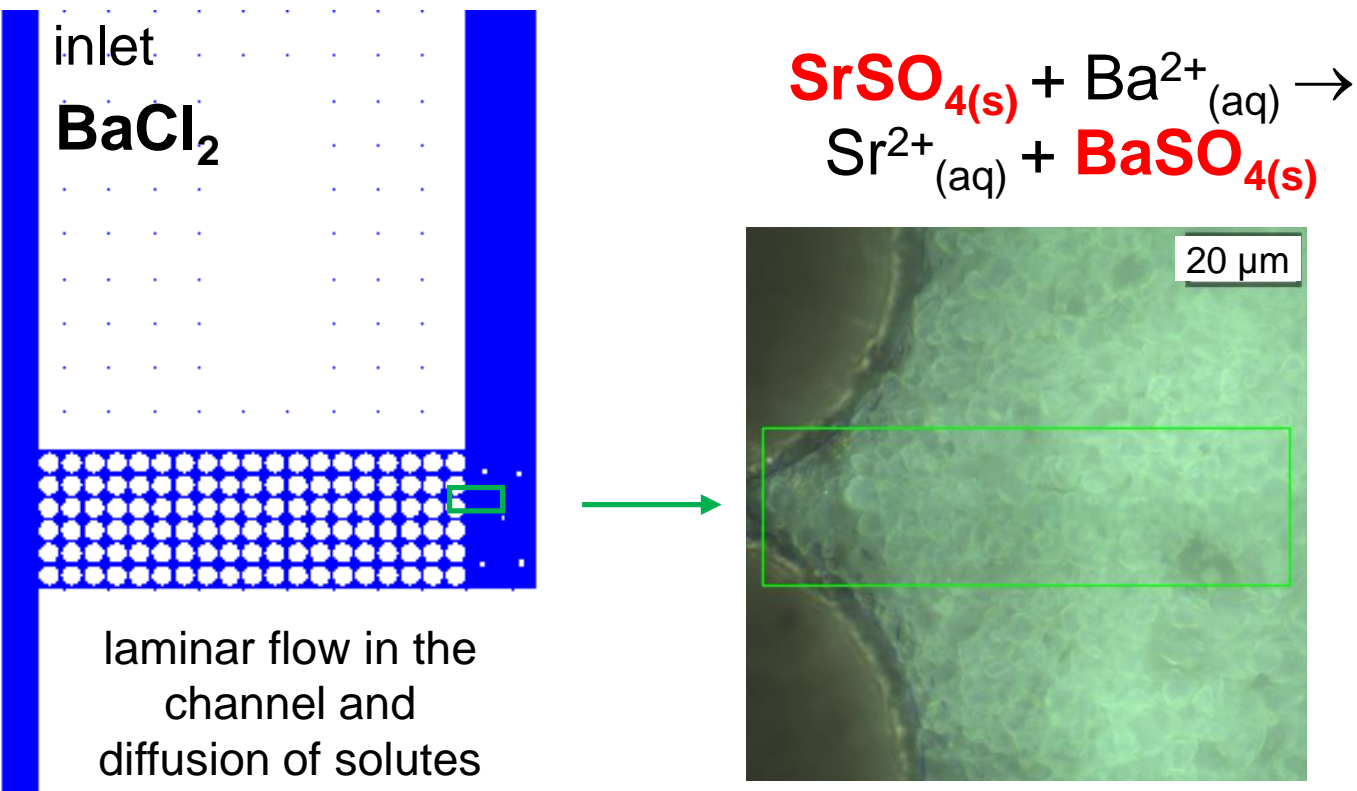

reservoir of $800 \mu \mathrm{m}$ $\times 450 \mu \mathrm{m} \times 1 \mu \mathrm{m}$ filled with $\mathrm{SrSO}_{4}$ crystals of size $4-9 \mu \mathrm{m}$

outlet 


\section{CHANGES IN PORE ARCHITECTURE}

\section{Raman imaging}
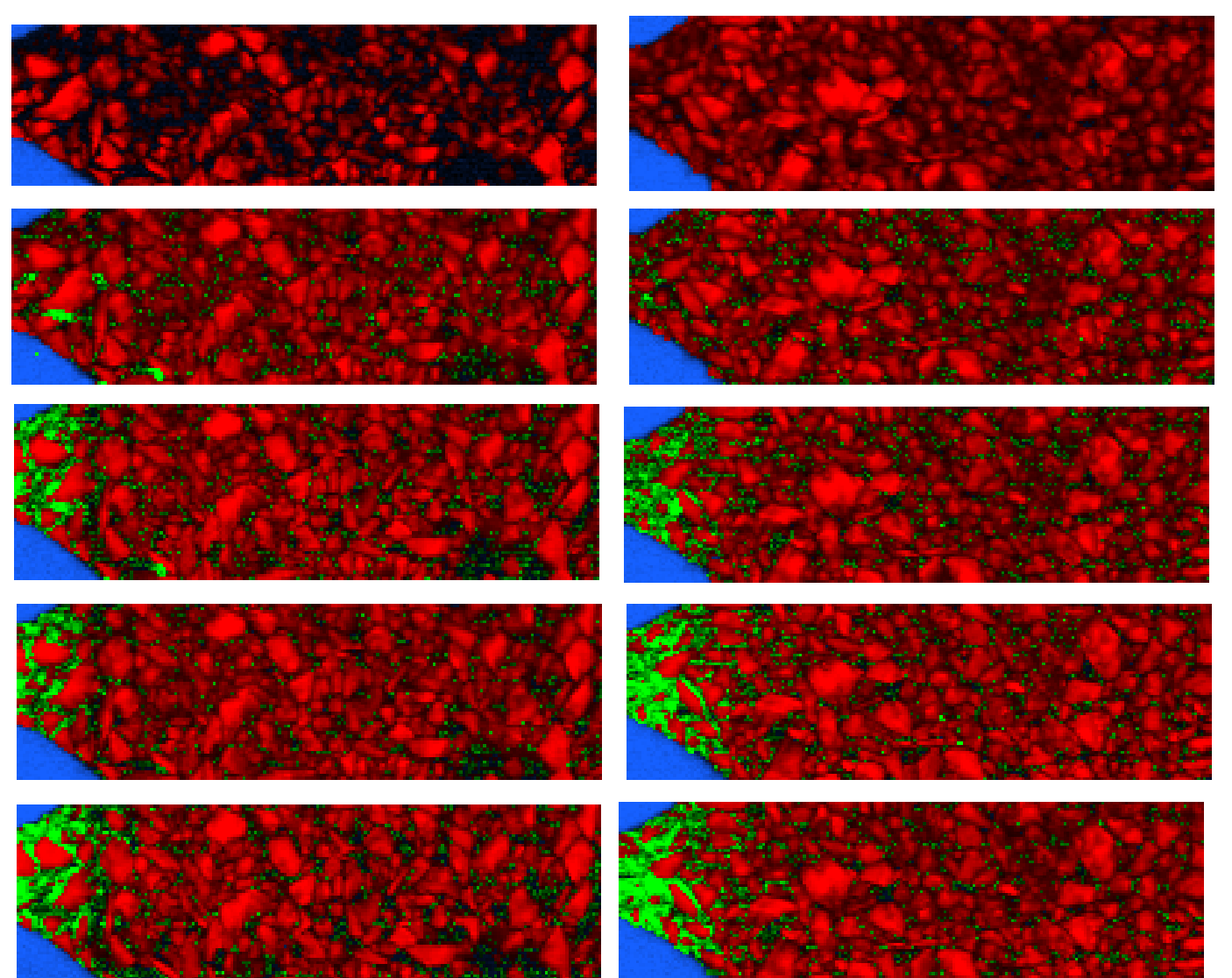

PDMS, $\mathrm{SrSO}_{4}, \mathrm{BaSO}_{4}$
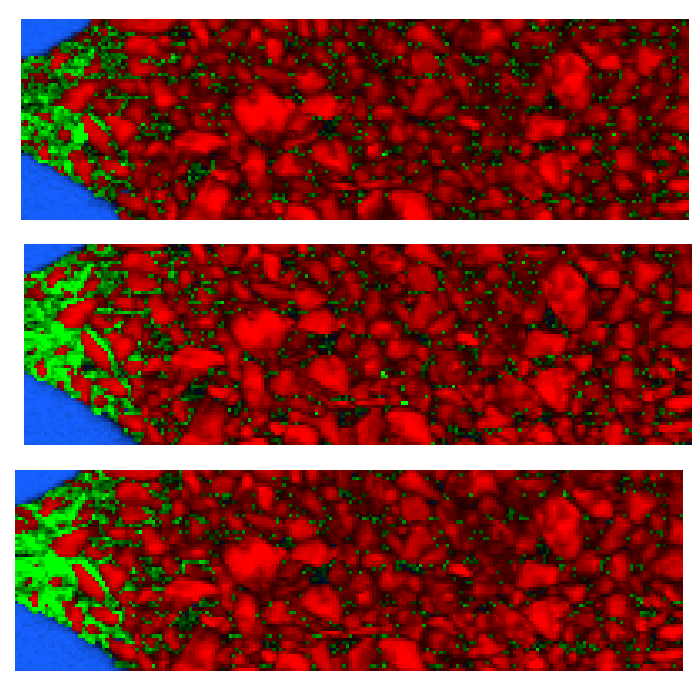

Raman tomographs
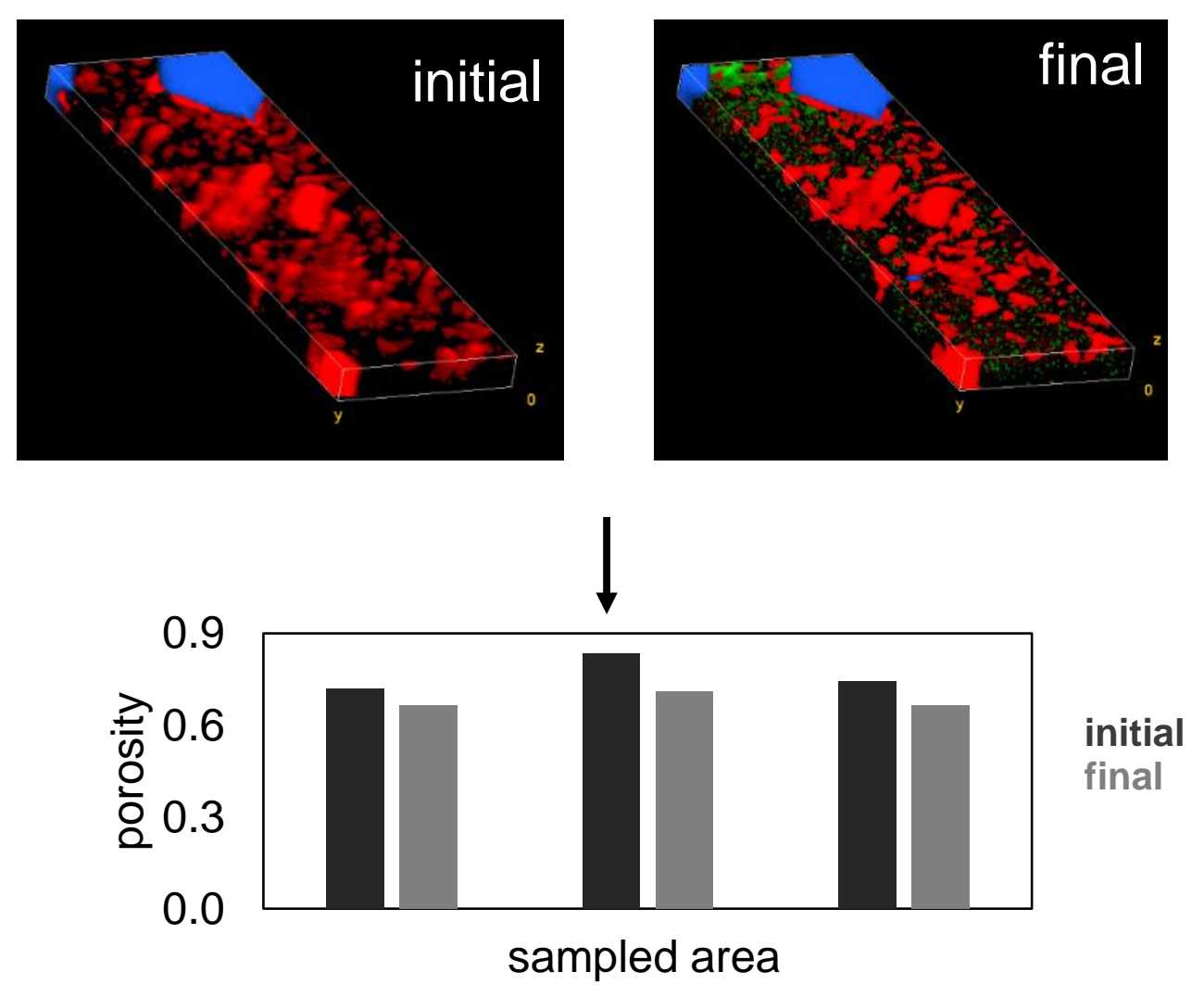

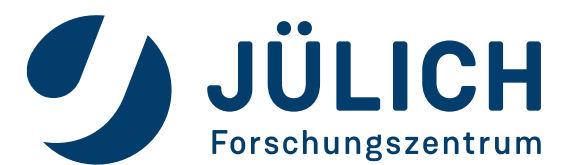




\section{EFFECTIVE DIFFUSION COEFFICIENT}

\section{Pore scale modelling using Lattice Boltzmann method (ongoing)}

\section{Experiment}

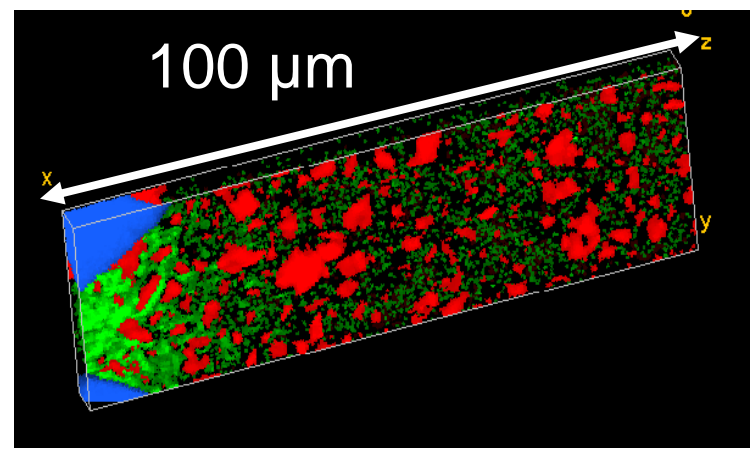

Pore scale modelling of tracer diffusion across the reacted porous medium to derive the effective diffusion coefficient $D_{\mathrm{e}}$

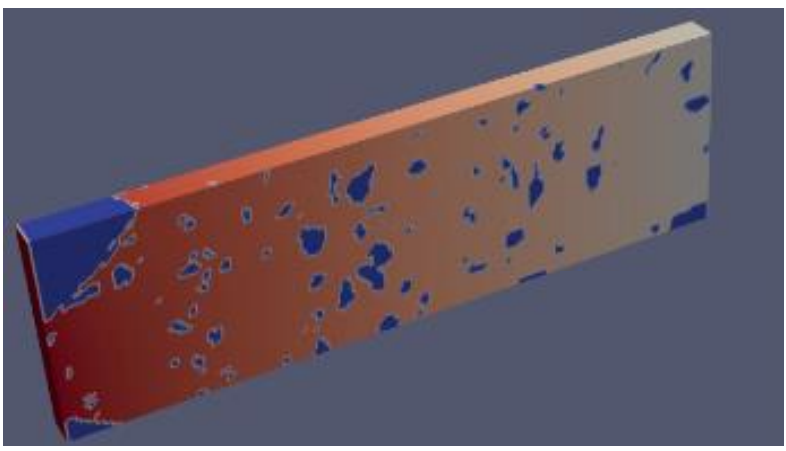

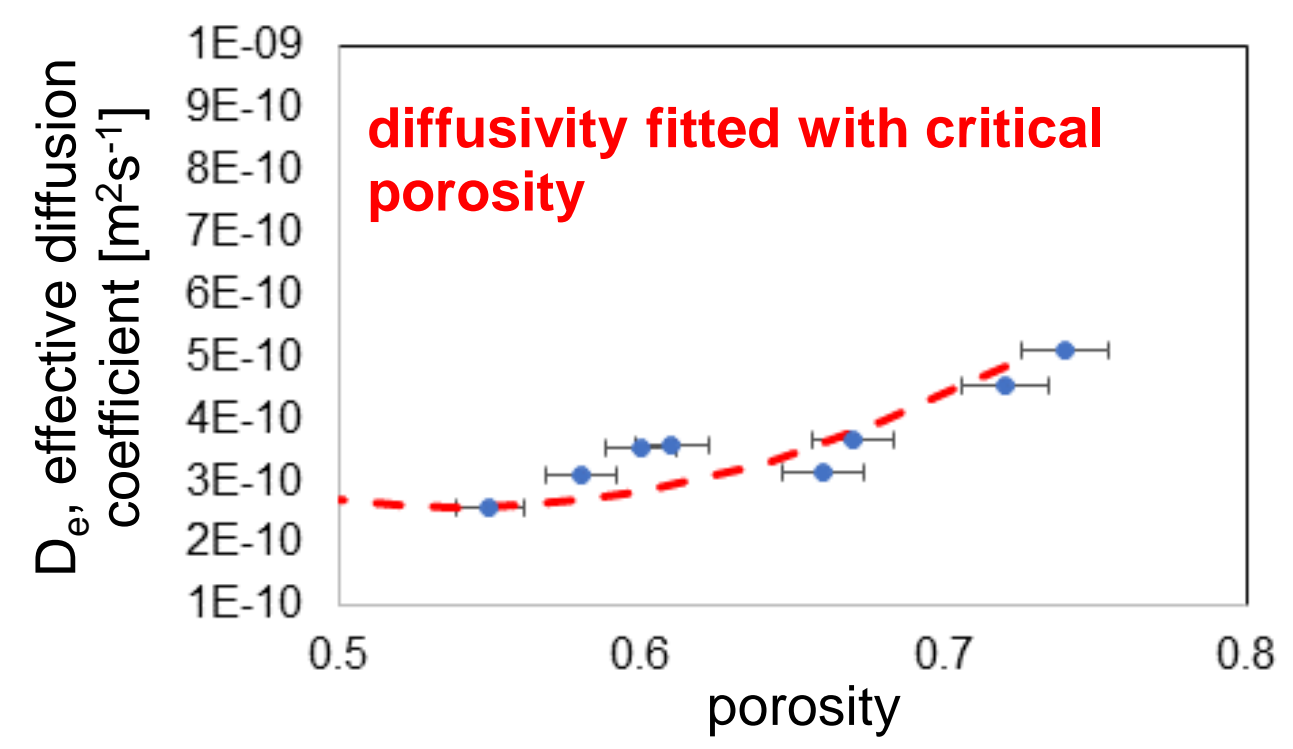

- Derivation of a porosity - diffusivity relationship Check poster of Mara Lönartz ( $11^{\text {th }}$ November, 14:20h) for porosity - diffusivity relationships 


\section{CONCLUSIONS}

Experimental investigations show limitations of classical approaches to model hydrogeochemical processes associated with porosity decrease in porous media

Investigations at the pore scale are necessary to understand and quantify the effects of crystallization mechanisms on porosity changes

There is a need to develop process-based predictive models and mathematical relationships that account for small scale heterogeneity and integration into larger scale analysis (upscaling) 


\section{THANK YOU FOR YOUR KIND ATTENTION ...}

The research leading to these results has received funding from the German Federal Ministry of Education and Research (BMBF, grant agreement 02NUK053A) and from the Initiative and Networking Fund of the Helmholtz Association (HGF grant SO-093) within the iCross project.

SPONSORED BY THE

Federal Ministry
of Education
and Research
HELMHOLTZ

RESEARCH FOR GRAND CHALLENGES 